Recent Spectrographic Observations of Nove.Using the slitless spectrograph recently attached to the Crossley reflector, Prof. Perrine has obtained photographs of the recent spectra of various novæ.

A spectrogram of Nova Aurigæ, taken with a total exposure of 5 hours on August 29 and 30, shows that important changes have taken place in the spectrum of this star since 1901, when the spectrum was photographed by Mr. Stebbins. At that time the chief nebular line at $\lambda$ 50 r was equal in intensity to the lines at $\lambda 462, \lambda 434$, and $\mathrm{H} \delta$, but in the recent photographs it is entirely absent; the other lines are relatively the same, but all appear to have decreased in intensity with regard to the continuous spectrum. This Nova is now of the fourteenth magnitude.

In the case of Nova Persei, a spectrum obtained on July 30 , with an exposure of 2 hours 3 minutes, shows that striking changes have taken place since March, 1902. H $\beta$ has decreased greatly in brightness during the interval, and the condensation at $\lambda 434$ has also become less marked, whilst $\mathrm{H} \delta$ has only suffered the normal diminution in brightness. The lines at $\lambda 339$ and $\lambda 346$ show the greatest changes, the former having entirely disappeared, whilst the latter is barely distinguishable on the latest spectrogram; the chief nebular line does not appear to have changed relatively to the general spectrum. On July 30 the magnitude of Nova Persei was about 11.5 or I2.

Even in the more recent Nova Geminorum important changes are already noticeable; photographs were secured on August 28, 3I, and September 2, and when compared with the observations of May II it was seen that during the interval of $3^{\frac{1}{2}}$ months the whole spectrum had become much weaker; the chief nebular line had become much stronger, whilst $\mathrm{H} \boldsymbol{\beta}$ had greatly decreased in relative intensity. The line at $\lambda 434$ is by far the strongest in the 'whole spectrum, and that at $\lambda 463$ is much broadened and probably composite; there are also indications of the higher hydrogen lines on the background of continuous spectrum. On a number of spectrograms obtained between April 2 and 8 a condensation at $\lambda 35^{\circ}$ was a remarkable feature, on April i 8 no indications of this condensation were present, whilst on April 26 there was a strong condensation at $\lambda 346$, but nothing at all at $\lambda 350$; later observations confirm this interesting phenomenon.

Visual observations of the spectrum of Nova Geminorum, made by $\mathrm{Mr}$. H. D. Curtis on August $I 7$ and 18 with spectrograph No. 1 attached to the 36 -inch refractor, showed the three chief nebular lines well developed, $\mathrm{H} \beta$ faint, the line at $\lambda 4959$ rather stronger, and the line at $\lambda 5007$, into which the greater part of the Nova's light seemed to be concentrated, very much more intense, whilst $D$ and $\mathrm{Ha}$ were not visible. The change of this star into one of the nebular type is apparently now complete (Lick Observatory Bulletin, No. 48 ).

Occultation of a StaR by Jupiter.-A communication to the Kiel Centralstelle, published in No. 3903 of the Astronomische Nachrichten, announced that Mr. T. Banachiewicz, of the Warsaw University, had observed an occultation of the star B.D. $-6^{\circ} .6191$ (mag. $=6.5$ ) by Jupiter at about th. Iom. (Berlin M.T.) on September io.

Several observers recorded their observations of this phenomenon in No. 3906 of the Nachrichten, amongst others Herr Kostinsky, of the Pulkowa Observatory, who gave the times of immersion and emergence as 2oh. rom. 2rs. \pm Is. and 2 rh. $52 \mathrm{~m} .4 \mathrm{~s} \pm$ Is. (Pulkowa S.T.) respectively.

In a letter to the October number of the Observatory, $\mathrm{Mr}$. Denning gives the details of his observations of the phenomenon about half an hour after the probable reappearance of the star, when it was situated at about 10 $^{\prime \prime}$ from the S.S.E. limb of the planet. He states that the same star will be about $20^{\prime}$ south of Jupiter on December 29 at approximately ıoh. G.M.T.

Rotational Velocitx of Venus.-Bulletin No. 3 of the Lowell Observatory contains a description, by $\mathrm{Mr}$. V. M. Slipher, of some experiments made at that observatory in order to determine, by the Deslandres spectrographic method, whether Venus has a short rotational period or not.

The instrument used was the new Lowell spectrograph, made by Brashear, which gives an angular dispersion of $46^{\prime \prime} \cdot 5$ for one tenth-metre when set for the minimum devi- ation of $\lambda 4270$. The spectrograph is so attached to the adapter that it may be rotated about the optical axis in order to obtain spectrograms with the slit in various relative positions; the plates used were fine-grain Seed's " 23 " brand, and were exposed for about 8 minutes during the hour immediately succeeding sunset, whilst the air currents were most quiescent. For purposes of measurement an iron spectrum was photographed on the same plate, and twelve of the finest iron lines were used as fiducial lines. The results obtained show very small probable errors, and indicate that Venus does not possess a short period of rotation. A period of twenty-four hours would cause an inclination of the lines amounting to one-third of a degree, and similar experiments performed on the planet Mars, and published in Bulletin No. 4, show that a longer period than this would be clearly indicated by the apparatus and method used.

\section{THE STANDARDISATION OF ELECTRICAL PRESSURES AND FREQUENCIES.}

$W E$ have received a copy of the resolutions of the Engineering Standards Committee with reference to standard pressures for direct current and standard frequencies. In view of the importance of the subject to the electrical industry at large, the document is reprinted below in full.

\section{Standard Direct Current Pressures and Standard} Frequencies.

The standardisation of electrical pressures and frequencies was the first portion of the important work entrusted to the subcommittee on generators, motors and transformers by the electrical plant committee. The subcommittee consists of the following gentlemen :-

Colonel R. E. Crompton, C.B., chairman.

Colonel H. C. Holden, R.A., Captain A. H. Dumaresq, R.E., representing the War Office.

Commander G. L. Sclater, R.N., Mr. L. J. Steele, representing the Admiralty.

Mr. Llewellyn Preece, representing the Crown Agents for the Colonies.

Dr. R. T. Glazebrook, representing the National Physical Laboratory.

Mr. B. H. Antill, Mr. W. B. Esson, nominated by the Electrical Engineers' Plant Manufacturers' Association.

Mr. A. C. Eborall.

Mr. S, Z. de Ferranti.

Tr. Robert Hammond.

Captain H. R. Sankey.

Mr. C. H. Wordingham.

Mr. Leslie S. Robertson, secretary.

Mr. C. le Maistre, electrical assistant secretary.

At an early stage in their deliberations, the subcommittee decided that the most advantageous method of approaching this problem, beset as it is with so many difficulties, would be from the point of view of those most affected, namely the users of lamps and of motors for power purposes. It was therefore agreed that the standard pressures to be suggested should be measured at the consumers' terminals as settled by Act of 1899 .

At the present time there exist many different pressures declared by the various lighting and power authorities. In view of the great desirability of obviating this unsatisfactory state of affairs it was deemed advisable to suggest the minimum number of standard pressures which would best meet present commercial requirements and, at the same time, utilise to the fullest extent the consumers' existing appliances.

After careful consideration, it became evident to the subcommittee that the direct current pressures of $110,220,440$, and 500 volts would best meet the requirements, because carcases built for these standard pressures could be utilised carcases built for these standard pressures could be utilised standards, without any alteration whatever in the castings or mechanical components, by merely altering the windings and excitation.

It is to be hoped that now these direct current pressures have been fixed as standards by the committee, they will in future be universally adopted by the engineers advising

No. 1774 , vOL. 68] 
corporations and others distributing electrical energy. In course of time the benefits to the electrical industry at large which will certainly follow the adoption of these standard pressures, must become more and more apparent.

A circular was drafted embodying the suggestions of the subcommittee, and this was submitted, first to the manufacturers for their consideration, and secondly to the leading consulting engineers and users of motors.

The information so courteously placed at the disposal of the subcommittee by the consulting engineers and manufacturers was most carefully weighed and considered by the subcommittee, and certain definite conclusions were arrived at, the circular being sent, in the first instance, to the manufacturers, as they were the people most directly interested. Replies were received from all the leading firms, who expressed themselves unanimously in favour of the recommendations of the subcommittee. The consulting engineers similarly gave their adherence to the proposals of the subcommittee.

Before coming to their final decision the subcommittee on generators, motors and transformers conferred with the subcommittee on electrical tramways, of which Mr. A. P. Trotter is chairman, and a joint meeting took place, with the result that the pressure of 500 volts, which most concerned the latter subcommittee, was agreed to, and in addition to the pressures already agreed to 600 volts was decided upon as the standard pressure for electrical railways.

The question of the adoption of standard frequencies, although of equal importance with that of standard pressures, was not surrounded with the same difficulties. It was, however, deemed advisable to fix upon the standard frequencies at the earliest possible stage of the work, as no progress could be made in the standardisation of prime movers for driving alternate current machinery until such time as the frequencies had been settled upon. On this question there appeared to be a great preponderance in favour of frequencies of 25 and 50 . The only point upon which any serious difference of opinion appeared to exist was the advisability of the adoption of a third frequency of 40 or 42 , to enable rotary converters to be used to the fullest advantage. All the arguments in favour of this third frequency were fully discussed, but after carefully weighing the pros and cons the subcommittee decided not to rernmmend the adoption of more than two frequencies, namely, 25 and 50.

The recommendations of the subcommittee were then submitted to the electrical plant committee, the publication committee, the main committee, and the Board of Trade for their approval.

This having been obtained, it was deemed advisable, in the interests of the electrical industry of the country, that the findings on the questions of direct current pressures and frequencies should be published at an early date, without waiting for the completion of the entire report to be issued at a later date.

The following are the resolutions on standard direct current pressures and standard frequencies:-

(I) That the standard direct current pressures, measured at the consumers' terminals, be :-

$$
\text { I ro, } 220,440,500 \text { volts. }
$$

(2) That the standard direct current pressures, measured at the terminals of the motors, be :-

$$
\begin{aligned}
& \text { For tramways } 500 \text { volts. } \\
& \text { For railways } 600 \text { volts. }
\end{aligned}
$$

(3) That 25 periods per second be the standard frequency for :-

(a) Systems involving conversion to direct current by means of rotary converters.

(b) Large power schemes over long distances.

(c) Three phase railway work, where motor gearing and the inductive drop on the track rail have to be considered.

(4) That 50 periods per second be the standard frequency for :-

(a) Mixed power and lighting on town supply mains.

(b) Ordinary factory power plant.

(c) All medium size power plant where rotary converters are not employed.

No. 1774 , vOL. 68$]$

\section{GEOGRAPHY AT THE BRITISH ASSOCIATION.}

THE present transitional phase of geographical thought and activity was faithfully mirrored in the proceedings of Section E. The majority of the papers revealed the wide range of geographical interests rather than any great advance in geographical coordination. In this they are typical; for while there are many workers at geographical problems, few, if any, would put forth the claim of being complete geographers. There are indications of many geographical specialisms being recognised. Their exponents are, however, at one disadvantage when compared with other specialists. An organic chemist usually has had a thorough training in chemistry before he specialises in organic chemistry. Few geographical specialists have had any training as geographers. Each makes his own contribution, but it is often an isolated one, and does not fit into a general plan of the subject. The unity of geography and the relation of its parts are very gradually being elucidated. The want of this coordination is strongly felt by most geographical workers. At the conclusion of the Southport meeting one wished for a summary coordinating the communications discussed. Perhaps this is felt though to a less extent, in other sections, and it would be useful if the presidential duties were made to conclude by the giving of a brief review of the work done at the section.

The address of the genial president, Captain Creak, was the only one which surveyed the whole world. It was on terrestrial magnetism, and has already been printed. Dr. Vaughan Cornish's researches, summarised in the report of the committee on terrestrial surface waves, are on worldwide phenomena, which he illustrated on this occasion mainly by beautiful views of the wave forms of Niagara, from which he has recently returned, and by pictures of wave forms in snow and on quarry roads caused by heavy sledge traffic.

The section was also privileged to hear an address from Prof. Pettersson, of Stockholm, who spoke for an hour in excellent English, on the effect of ice melting on oceanic circulation. Prof. Pettersson has long insisted that the thermodynamic cycle of latent heat, consisting of ice formation in polar regions and of ice melting in sea-water in lower latitudes, was a potent cause of oceanic currents. $\mathrm{H}$ ? has calculated that the ice melting between Iceland and Jan Mayen generates about 400,000 horse-power annually, which is expended in accelerating the water movements of the east Iceland polar current. The energy set free on ice melting in sea-water maintains a kind of inverted waterfall, an upwelling of bottom water to the surface. Warm currents follow the trend of deepest isobaths, ice currents exist only in shallow seas, where no warm current can melt them. Ice currents and warm currents meet between Iceland and Jan Mayen, west of Spitsbergen, southeast of Newfoundland, and round the margin of the icegirdled Antarctic. The " outbursts" of Antarctic icebergs which carry them to low latitudes in the Indian Ocean may influence the climate of India and Australia. The latest Antarctic outburst and series of great droughts in India occurred between $1891-98$. Prof. Pettersson considered that regular surface observations between $60^{\circ}$ and $100^{\circ}$ E. and a few series of deep-sea soundings would reveal hydrographical variations with important meteorological bearings. He also pointed out that current measurements at depths of $800-4000$ metres in the Atlantic were needed to ascertain the significance of the currents generated by ice attraction. At the conclusion of his paper Prof. Pettersson showed in miniature an experiment to illustrate the effect of melting ice in causing currents in salt water carried out by Mr. J. W. Sandström, assisted by Miss A. Palmquist, who have made a series of useful calculations from the data obtained from this experiment.

Travellers' tales were few, but full of human interest. No one who heard Lieutenant Shackleton will forget the vivid and racy account he gave of the National Antarctic Expedition. Dr. Tempest Anderson's slides and descriptions of the volcanic phenomena of St. Vincent and Martinique were equally effective. Lieut.-Colonel Manifold described his journeying from India across China, and back over different routes through the heart of the Empire. In his paper were many hints of the great activity of other Powers 